Article

\title{
Investigating the Relationship between White Matter Connectivity and Motivational Circuits in Subjects with Deficit Schizophrenia: A Diffusion Tensor Imaging (DTI) Study
}

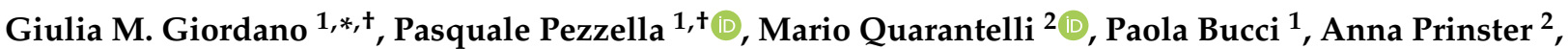 \\ Andrea Soricelli ${ }^{3,4}$, Andrea Perrottelli ${ }^{1}$, Luigi Giuliani ${ }^{1}$, Michele Fabrazzo ${ }^{1}$ (D) and Silvana Galderisi ${ }^{1}$ \\ 1 Department of Psychiatry, University of Campania “Luigi Vanvitelli”, 80138 Naples, Italy; \\ pezzella.pasquale3@gmail.com (P.P.); paolabucci456@gmail.com (P.B.); andreaperrottelli@gmail.com (A.P.); \\ luigi.giuliani.91@gmail.com (L.G.); michele.fabrazzo@unicampania.it (M.F.); \\ silvana.galderisi@gmail.com (S.G.) \\ 2 Biostructure and Bioimaging Institute, National Research Council, 80134 Naples, Italy; \\ quarante@unina.it (M.Q.); anna.prinster@ibb.cnr.it (A.P.) \\ 3 Department of Integrated Imaging, IRCCS SDN, 80143 Naples, Italy; andrea.soricelli@uniparthenope.it \\ 4 Department of Motor Sciences and Healthiness, University of Naples Parthenope, 80133 Naples, Italy \\ * Correspondence: giuliamgiordano@gmail.com; Tel.: +39-0815666512; Fax: +39-0815666523 \\ + These authors contributed equally to this work.
}

check for updates

Citation: Giordano, G.M.; Pezzella, P.; Quarantelli, M.; Bucci, P.; Prinster, A.; Soricelli, A.; Perrottelli, A.; Giuliani, L.; Fabrazzo, M.; Galderisi, S. Investigating the Relationship between White Matter Connectivity and Motivational Circuits in Subjects with Deficit Schizophrenia: A Diffusion Tensor Imaging (DTI) Study. J. Clin. Med. 2022, 11, 61. https://doi.org/10.3390/ jcm11010061

Academic Editors: Armida Mucci and Birgit Derntl

Received: 26 November 2021

Accepted: 22 December 2021

Published: 23 December 2021

Publisher's Note: MDPI stays neutral with regard to jurisdictional claims in published maps and institutional affiliations.

Copyright: (C) 2021 by the authors. Licensee MDPI, Basel, Switzerland. This article is an open access article distributed under the terms and conditions of the Creative Commons Attribution (CC BY) license (https:// creativecommons.org/licenses/by/ $4.0 /)$

\begin{abstract}
Deficit schizophrenia is a subtype of schizophrenia presenting primary and enduring negative symptoms (NS). Although one of the most updated hypotheses indicates a relationship between NS and impaired motivation, only a few studies have investigated abnormalities of motivational circuits in subjects with deficit schizophrenia (DS). Our aim was to investigate structural connectivity within motivational circuits in DS. We analyzed diffusion tensor imaging (DTI) data from 46 subjects with schizophrenia (SCZ) and 35 healthy controls (HCs). SCZ were classified as DS $(n=9)$ and nondeficit (NDS) $(n=37)$ using the Schedule for Deficit Syndrome. The connectivity index (CI) and the Fractional Anisotropy (FA) of the connections between selected brain areas involved in motivational circuits were examined. DS, as compared with NDS and HCs, showed increased CI between the right amygdala and dorsal anterior insular cortex and increased FA of the pathway connecting the left nucleus accumbens with the posterior insular cortex. Our results support previous evidence of distinct neurobiological alterations underlying different clinical subtypes of schizophrenia. DS, as compared with NDS and HCs, may present an altered pruning process (consistent with the hyperconnectivity) in cerebral regions involved in updating the stimulus value to guide goal-directed behavior.
\end{abstract}

Keywords: motivation circuits; negative symptoms; RDoC; positive valence system; salience system; schizophrenia; deficit syndrome

\section{Introduction}

Negative symptoms represent a core aspect of schizophrenia, with a negative impact on the functioning of people suffering from this disorder. To date, they remain an unmet therapeutic need, since no effective treatment is available for these symptoms, particularly when they are primary to the disorder [1-14].

According to the current conceptualization provided by the Consensus Conference of the National Institute of Mental Health-Measurement and Treatment Research to Improve Cognition in Schizophrenia (NIMH-MATRICS), the negative symptom construct includes five individual symptoms, namely avolition, anhedonia, asociality, blunted affect and alogia [15]. These symptoms cluster into two domains, the Experiential domain (which includes avolition, anhedonia and asociality) and the Expressive Deficit domain (which includes blunted affect and alogia) [4,13-20].

Negative symptoms might be the primary manifestation of schizophrenia (primary negative symptoms) or the consequence of different factors (secondary negative symptoms), 
i.e., psychopathological factors (moderate positive symptoms, clinically significant depression), syndrome-unrelated factors (social isolation, environmental hypostimulation) or medication side effects (extrapyramidal symptoms and sedation), and might be transient or persistent over time. Primary and persistent negative symptoms characterize a subtype of schizophrenia, named deficit schizophrenia, which is associated with a greater impairment of general cognitive functions and poorer treatment response and outcome, in comparison with non-deficit schizophrenia [21-30].

One of the most updated neurobiological hypotheses underlying negative symptoms indicates a relationship between the Experiential domain and an impairment in different aspects of motivation [4,27,31-42]. Indeed, subjects with schizophrenia show impairments in several aspects of motivation, except for the pleasure experience [31,32,34-36]. Notably, patients show greater difficulty in reward-related learning and adaptive integration of value information with action selection $[43,44]$, which could be linked to an alteration of the connectivity between brain areas involved in the dopaminergic circuits. On the other hand, the Expressive Deficit domain is less understood and probably is related to deficits in neurocognitive and social cognition abilities-often observed in subjects with schizophrenia, particularly in subjects with a high genetic risk for schizophrenia [5,7,45-51]—and to neurological soft signs, suggesting that Expressive Deficit symptoms, akin to cognitive deficits, are probably driven by a diffuse neurodevelopmental disconnectivity $[4,52,53]$.

Two possible mechanisms and circuits might be implicated in the pathophysiology of motivational deficits in subjects with schizophrenia: an impairment in the "motivational value system or reward circuit" (NIMH Research Domain Criteria "positive valence system") and/or an impairment in the "motivational salience circuit". The brain areas belonging to the motivational value system are the ventral tegmental area (VTA) and the ventro-medial substantia nigra pars compacta (VMSNpc), which project to the nucleus accumbens shell (sNAcc), the dorsal striatum (DStr), the medial orbito-frontal cortex (mOFC) and the ventro-medial prefrontal cortex (VMPFC) $[4,33,39]$. Abnormalities in these areas and/or in their connections may result in an impairment in anticipatory pleasure, action evaluation and encoding of the value of stimuli, action outcome contingency learning (the ability to know the causal consequences of an action) and instrumental learning (the integration of value with action selection) [4].

The motivational salience system includes the VTA and the dorso-lateral substantia nigra pars compacta (DLSNpc) with projections to the accumbens core (cNAcc), which, in turn, projects to the DSr, the dorso-lateral prefrontal cortex (DLPFC), the ventro-lateral prefrontal cortex (VLPFC) and the anterior cingulate cortex (ACC) [33]. Abnormalities in these areas and/or in their connections might lead to an impairment in general and energetic aspects of motivation, vigor in motivated behavior, cognitive activation and the ability to orient oneself towards salient stimuli $[4,33,54-57]$. The identification of biobehavioral data associated with specific psychopathological features might refine hypotheses on negative symptoms [58], clarify the relationships with cognitive impairment and pave the way towards innovative treatment options for some of these symptoms [59].

Although several brain regions are part of these two interconnected circuits (motivational value and salience systems), the nucleus accumbens (NAcc) and the VTA represent key central regions within these circuits $[60,61]$. Other brain structures interconnected with these circuits are the amygdala (Amy) and hippocampus [62,63].

As far as we know, only rarely have these pathophysiological models of negative symptoms been applied to the deficit schizophrenia construct $[4,37,64]$. In particular, one study [64] reported the presence in subjects with deficit schizophrenia of structural brain abnormalities in several brain areas, such as the insula, anterior cingulate cortex, medial prefrontal cortex and putamen, which are involved in motivation and goal-directed behavior. In a functional magnetic resonance imaging study during a reward anticipation task, Mucci and colleagues [37] reported that subjects with deficit schizophrenia showed a significant reduction in dorsal caudate activity, compared with both healthy controls and subjects with non-deficit schizophrenia. 
Diffusion tensor imaging (DTI) studies have highlighted the presence of "disconnectivity" within and between cortical and subcortical areas in subjects with schizophrenia and in those with psychotic disorders [37,39,40,65-73]. This disconnectivity might lead to abnormalities in those pathways that underlie cognitive abilities and motivated behavior $[65,74]$.

In subjects with deficit schizophrenia, white matter (WM) abnormalities in the superior longitudinal fasciculus [75], left uncinate fasciculus [76,77], right inferior longitudinal fasciculus, right arcuate fasciculus [77], postcentral area, left forceps minor [78], right posterior thalamic radiation [79] and posterior corpus callosum [80] have been reported.

However, these studies did not investigate abnormalities of motivational circuits in subjects with deficit schizophrenia, since this was not the primary objective of these studies. Furthermore, some of the above-mentioned studies [77,79,80] did not use the Schedule for the Deficit Syndrome (SDS), which represents the gold standard to assess deficit schizophrenia, but they instead used a proxy from the Positive and Negative Syndrome Scale (PANSS) [81]. However, it has been demonstrated that the proxy for categorizing patients in subjects with deficit and non-deficit schizophrenia has some problems in terms of face validity and temporal stability [14]. In addition, the PANSS includes some aspects that are not conceptualized as negative symptoms and evaluates symptoms belonging to the Experiential domain only at a behavioral level.

Therefore, in light of the above observations, our study aimed to fill the gap in the previous literature, investigating, in subjects with deficit schizophrenia (assessed with a state-of-the-art instrument), the presence of abnormalities within motivational circuits. To this aim, using a bilateral probabilistic approach on DTI data, the present study examined differences between subjects with deficit schizophrenia, subjects with non-deficit schizophrenia and healthy controls in WM connections between major brain regions involved in motivational pathways. We hypothesized that subjects with deficit schizophrenia would show abnormalities in WM connections between brain areas involved in motivational circuits, compared to subjects with non-deficit schizophrenia and healthy controls.

\section{Materials and Methods}

\subsection{Subjects}

Fifty-two subjects with schizophrenia (SCZ) were enrolled at the Department of Psychiatry of the University of Campania "Luigi Vanvitelli", in the period between September 2010 and July 2012. All subjects were right-handed.

The inclusion criteria were as follows:

- $\quad$ diagnosis of schizophrenia based on the criteria of the DSM-IV, confirmed by the Mini International Neuropsychiatric Interview Plus (MINI-Plus);

- $\quad$ age between 18 and 65 years;

- $\quad$ negative history of intellectual disability, head trauma with unconsciousness, alcohol or substance abuse within the previous six months (except for cigarette smoking);

- no treatment modifications and/or hospitalization due to symptom exacerbation in the last three months;

- $\quad$ treatment with second-generation antipsychotics [82].

Thirty-five right-handed healthy controls (HCs) were included. The subjects were enrolled from the community through the distribution of informative leaflets. Exclusion criteria for HCs were:

- $\quad$ presence of current or lifetime Axis I or II psychiatric diagnosis; history of psychiatric hospitalization;

- $\quad$ history of head trauma with unconsciousness;

- history of substance abuse or dependence (except for cigarette smoking) and use of drugs that affect the central nervous system. 
The study was approved by the University Ethics Committee. All participants signed a written informed consent form after a detailed description of the study procedures and goals.

The study was performed in accordance with the ethical principles of the Declaration of Helsinki.

A subsample of thirty-five SCZ and seventeen HCs was included in a previous publication [40].

\subsection{Assessment Instruments}

Socio-demographic variables such as age, paternal and maternal education and gender were evaluated for all subjects. A semi-structured interview, the Schedule for the Deficit Syndrome [83], was used to categorize patients as subjects with deficit schizophrenia (DS) and subjects with non-deficit schizophrenia (NDS). In particular, deficit schizophrenia was diagnosed when subjects had at least two out of six primary negative symptoms (curbing of interests, diminished sense of purpose, diminished social drive, restricted affect, diminished emotional range and poverty of speech) for at least 12 months, including periods of clinical stability. Positive symptoms, depression and disorganization were assessed using the Positive and Negative Syndrome Scale [81].

The daily antipsychotic dose was converted to chlorpromazine equivalents, according to Gardner et al. [84].

\subsection{MRI Acquisition and Parameters}

We recorded all MRI with a 3 T scanner (Achieva, Philips Medical Systems, Best, The Netherlands), and we acquired DTI data using an EPI sequence (repetition time/echo time (TR/TE) 9300/102 ms, voxel $2 \times 2 \times 2 \mathrm{~mm}^{3}, 32$ directions uniformly distributed in 3-dimensional (3D) space 25, B-factors 0 and $1000 \mathrm{~s} / \mathrm{mm}^{2}, 50$ axials slices covering the whole brain). In addition, we obtained a 3D T1-weighted brain volume (Turbo-Field-Echo sequence, TR/TE $7.7 / 3.5 \mathrm{~ms}$, voxel $1 \times 1 \times 1 \mathrm{~mm}^{3}$, 181 sagittal slices covering the whole brain) to improve the spatial normalization of the data to the MNI space (see below). During the MRI acquisition, subjects were lying on their back with their heads lightly fixed by straps and foam pads to minimize head movement.

\subsection{Region of Interest}

We choose a set of ROIs relevant to the reward system for tractographic analysis, following the approach proposed by Bracht et al. [85], integrated by a set of insular ROIs. We defined the following ROIs bilaterally as seeds: NAcc (5 mm radius sphere, MNI coordinates of the center $\pm 8,11,-9$ ) [86], Amy (as defined in the WFUPick-Atlas) [87], VTA (4 mm radius sphere, MNI coordinates of the center $\pm 5,-20,-10$ ) [88]. Then, we defined the following as target ROIs: mOFC, lateral orbito-frontal cortex (1OFC), DLPFC, along with ventral-anterior (vaIC), dorsal-anterior (daIC) and posterior (pIC) insular cortex.

- $\quad$ Left and right DLPFC were defined combining on each side the Brodmann areas 9 and 46 [89], as defined in the WFUPick-Atlas.

- Orbito-frontal cortices were preliminarily obtained by combining the Brodmann areas 10 and 11, as defined in the WFUPick-Atlas, and were then divided on each side of the brain in their medial (mOFC) and lateral (lOFC) parts using the sagittal planes placed $20 \mathrm{~mm}$ off-center as separators [90].

- $\quad$ For each side, vaIC, daIC and pIC ROIs were obtained by dividing the entire available ROIs of insular cortex in the Harvard-Oxford Cortical Structural Atlas [91], based on its connectivity [92]. DTI pre-processing and probabilistic tractography were performed using the software modules provided in the FMRIB Software Library (FSL, http:/ / fsl.fmrib.ox.ac.uk/fsl, accessed on 15 July 2017). 


\subsection{Probabilistic Tractography}

We preliminarily corrected all DTI datasets for head movements using the eddy_correct routine implemented in FSL [93], thereby correcting accordingly diffusion sensitizing gradient directions [94]. A brain mask was obtained from the B0 images using the Brain Extraction Tool routine [95], and a diffusion tensor model was fitted at each voxel using FSL's algorithm for Bayesian Estimation of Diffusion Parameters Obtained using Sampling Techniques (BEDPOSTX). From the parameters of affine co-registration (translation along and rotation around the 3 axes), the mean movement over the brain mask was calculated for each of the 32 DTI volumes, as compared with the previous one. To avoid the effects of motion, which strongly influences apparent diffusion parameters, we excluded from the analysis datasets that exceeded at any time point $3 \mathrm{~mm}$ of head movement, and used mean head movement as a covariate in the second-level analysis (see below).

Then, we normalized the deskulled B0 volumes to the MNI space using the corresponding T1-weighted volumes as a proxy, using the 152 subject T1 template provided by SPM, and the FMRIB's Linear Image Registration Tool [96]. The resulting normalization matrices were inverted and applied to the ROIs (defined in the MNI space), to apply them to each patient's study. We assessed visually the quality of the normalization by verifying the match between normalized B0 volumes and the EPI template provided with SPM.

Then, we carried out probabilistic tractography using ProbTrackx [97], modeling 5000 iterations within each voxel of the seed ROI, with a curvature threshold (cosine of the minimum allowable angle between 2 steps) of 0.2 , a step length of 0.5 and a maximum number of 2000 steps. For each seed-target couple, we used the percentage of the total pathways starting from the seed that reached the target as a measure of the connectivity strength between the 2 ROIs (Connectivity Index, CI). In addition, we calculated the cumulated fractional anisotropy (FA) over each pathway in order to provide a measure of its structural integrity. Given the lack of consensus on this statistical issue, we did not use a threshold for either CI or FA calculations [98].

For each seed, only connections to homolateral target ROIs were examined.

\subsection{Statistical Analysis}

SPSS (Version 25.0, SPSS Inc, Chicago, IL, USA) was used to perform statistical analyses. A general linear model was fitted separately for each measure to assess differences between groups, including in the model as covariates age, gender and mean head movement (root mean square realignment estimates, RMS), as derived from the eddy_correct procedure. Bonferroni post-hoc comparisons between the three sample groups (HCs, DS and NDS) were performed when a significant main effect of the group emerged.

Results were considered significant for $p<0.05$, corrected according to Bonferroni for the number of connections assessed. In particular, as only homolateral connections were examined, a total of 36 seed-target couples were tested ( 3 seeds $\times 6$ targets $\times 2$ hemispheres), so that $p<0.0014$ was used as a statistical threshold.

\section{Results}

\subsection{Subject Characteristics}

We included only 46 patients and 35 HCs in the group-level analysis, as the MRI scans of six patients were discarded due to excessive motion artifacts during visual inspection. Please refer to Table S1 for the demographic and clinical characteristics of the whole sample of $\mathrm{SCZ}$, as compared to HCs.

According to the SDS criteria, the whole sample of SCZ was divided into DS $(n=9)$ and NDS $(n=37)$ patients. Table 1 summarizes the demographic and clinical characteristics of the three groups of the study sample (DS, NDS and HCs). There was no significant difference in the mean age $(p=0.149)$, gender $(p=0.268)$ or paternal $(p=0.057)$ and maternal $(p=0.265)$ education between DS, NDS and HCs. There was a small difference between the three groups in terms of RMS $(p=0.049)$. NDS, as compared to DS, had higher scores on PANSS Depression $(p=0.003)$. There was no statistically significant difference between DS 
and NDS on the SDS scores, although DS, as compared to NDS, had higher SDS total and subdomain scores.

Table 1. Demographic characteristics, RMS and illness-related variables of the study sample (HCs, NDS and DS).

\begin{tabular}{cccccc}
\hline & HCs $(\boldsymbol{n}=\mathbf{3 5})$ & NDS $(\boldsymbol{n}=\mathbf{3 7})$ & DS $(\boldsymbol{n}=\mathbf{9})$ & F & $p$ \\
\hline Age (years) & $32.94 \pm 8.80$ & $36.57 \pm 7.50$ & $33.00 \pm 8.53$ & 1.952 & 0.149 \\
\hline Gender (M/F) & $17 / 18$ & $25 / 12$ & $5 / 4$ & 1.340 & 0.268 \\
\hline Paternal education (years) & $11.31 \pm 5.85$ & $8.41 \pm 4.64$ & $9.00 \pm 4.09$ & 2.965 & 0.057 \\
\hline Maternal education (years) & $10.34 \pm 5.67$ & $8.49 \pm 4.69$ & $8.33 \pm 4.47$ & 1.352 & 0.265 \\
\hline RMS & $0.34 \pm 0.10$ & $0.41 \pm 0.10$ & $0.40 \pm 0.11$ & 3.131 & $\mathbf{0 . 0 4 9}$ \\
\hline Total SDS & - & $7.82 \pm 5.60$ & $11.00 \pm 6.70$ & 1.740 & 0.195 \\
\hline SDS Experiential domain & - & $4.76 \pm 3.45$ & $6.29 \pm 3.20$ & 1.161 & 0.288 \\
\hline SDS Expressive Deficit domain & - & $3.06 \pm 2.47$ & $4.71 \pm 3.59$ & 2.196 & 0.147 \\
\hline PANSS Positive & - & $8.09 \pm 4.28$ & $6.00 \pm 2.45$ & 1.541 & 0.222 \\
\hline PANSS Disorganization & - & $7.33 \pm 3.68$ & $7.43 \pm 4.28$ & 0.004 & 0.952 \\
\hline PANSS Depression & - & $2.49 \pm 0.85$ & $1.43 \pm 0.50$ & 10.224 & $\mathbf{0 . 0 0 3}$ \\
\hline Chlorpromazine equivalent doses & - & $402.01 \pm 190.05$ & $263.37 \pm 92.34$ & 3.003 & 0.092 \\
\hline
\end{tabular}

DS: patients with deficit schizophrenia; HCs: healthy controls; NDS: patients with non-deficit schizophrenia; PANSS: Positive and Negative Syndrome Scale; RMS: root-mean-square of the movement during the examination; SDS: Schedule for Deficit Syndrome. $p$ values in boldface indicate statistical significance. ${ }^{*}$ Bonferroni's post-hoc bivariate test: DS-HCs, $p=0.44$; NDS-HCs, $p=0.057$.

\subsection{Group Comparison on the Connectivity Index and Fractional Anisotropy between Couples} of ROIs

The results of the comparison on the $\mathrm{CI}$ and FA between SCZ and HCs are reported in Tables S2 and S3. In particular, SCZ, as compared to HCs, had a reduced CI between rAmy and homolateral DLPFC; however, this result did not survive correction for multiple tests $(p=0.004)$ (Table S2, Figures S1 and S2).

When we compared the three sample groups (DS, NDS and HCs), we observed a statistically significant difference in CI in the rAmy-daIC pathway $(p=0.001)$. Post hoc pairwise comparisons demonstrated that DS, as compared to NDS $(p=0.001)$ and HCs $(p=0.001)$, showed an increase in CI in the rAmy-daIC pathway, while no statistically significant difference was found between NDS and HCs (Table 2, Figures 1 and 2).

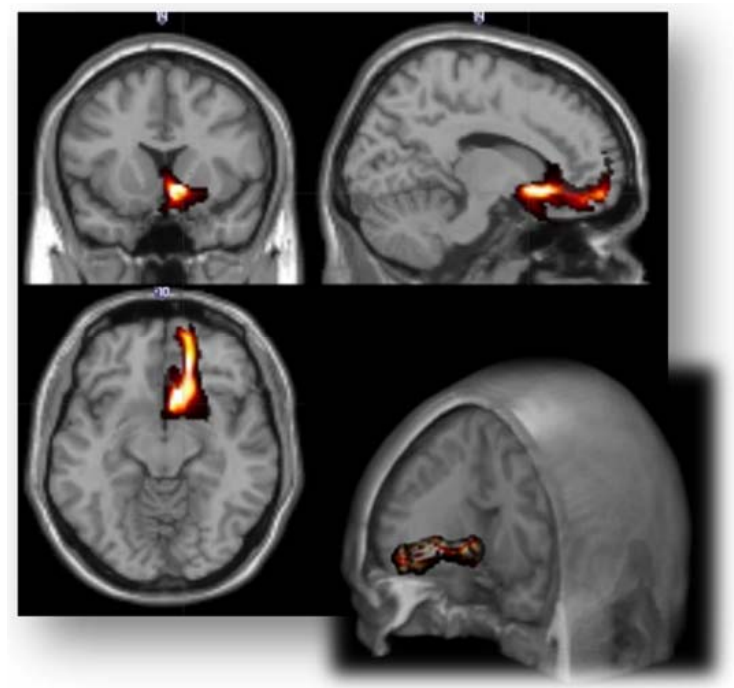

Figure 1. Three-dimensional representation of the average distribution of the connection patterns between the right amygdala and the ipsilateral dorsal anterior insular cortex. 
Table 2. Group differences between DS, NDS and HCs in CI.

\begin{tabular}{|c|c|c|c|c|c|}
\hline Brain Pathways & NDS $(n=37)$ & DS $(n=9)$ & HCs $(n=35)$ & $\mathbf{F}$ & $p$ \\
\hline \multicolumn{6}{|c|}{ CI } \\
\hline INAcc to daIC & $10.52 \pm 14.31$ & $6.02 \pm 6.64$ & $9.36 \pm 10.88$ & 0.831 & 0.440 \\
\hline INAcc to DLPFC & $41.35 \pm 54.84$ & $15.23 \pm 19.29$ & $49.31 \pm 101.35$ & 0.654 & 0.523 \\
\hline INAcc to $1 \mathrm{OFC}$ & $119.56 \pm 209.92$ & $105.95 \pm 116.48$ & $120.02 \pm 156.09$ & 0.114 & 0.892 \\
\hline INAcc to mOFC & $2192.74 \pm 1283.04$ & $1975.77 \pm 859.34$ & $2903.13 \pm 1783.21$ & 2.023 & 0.139 \\
\hline INAcc to pIC & $552.43 \pm 591.62$ & $1132.7 \pm 850.63$ & $463.43 \pm 408.79$ & 4.823 & 0.011 \\
\hline INAcc to vaIC & $646.07 \pm 509.67$ & $1246.7 \pm 1052.93$ & $920.0 \pm 881.79$ & 2.453 & 0.093 \\
\hline lAmy to daIC & $66.28 \pm 66.38$ & $29.66 \pm 24.57$ & $69.33 \pm 69.13$ & 1.532 & 0.223 \\
\hline 1Amy to DLPFC & $40.26 \pm 35.93$ & $23.7 \pm 17.01$ & $53.3 \pm 46.16$ & 1.795 & 0.173 \\
\hline lAmy to $1 \mathrm{OFC}$ & $160.01 \pm 175.11$ & $74.5 \pm 31.49$ & $14,328 \pm 160.88$ & 1.922 & 0.153 \\
\hline lAmy to mOFC & $832.51 \pm 547.32$ & $598.92 \pm 337.07$ & $1012.18 \pm 647.54$ & 1.662 & 0.197 \\
\hline 1Amy to pIC & $2231.79 \pm 1861.32$ & $3076.22 \pm 1806.24$ & $1748.80 \pm 1274.76$ & 3.323 & 0.041 \\
\hline 1Amy to vaIC & $2418.53 \pm 1169.48$ & $2452.89 \pm 916.74$ & $2908.10 \pm 1094.67$ & 1.424 & 0.247 \\
\hline IVTA to daIC & $57.8 \pm 89.75$ & $12.48 \pm 13.78$ & $33.06 \pm 41.98$ & 1.428 & 0.246 \\
\hline IVTA to DLPFC & $125.04 \pm 157.90$ & $76.05 \pm 100.19$ & $129.57 \pm 85.92$ & 1.101 & 0.338 \\
\hline IVTA to $1 \mathrm{OFC}$ & $90.15 \pm 79.93$ & $36.76 \pm 32.64$ & $126.96 \pm 140.15$ & 2.560 & 0.084 \\
\hline IVTA to $\mathrm{mOFC}$ & $66.57 \pm 67.51$ & $80.52 \pm 153.03$ & $102.19 \pm 131.15$ & 1.027 & 0.363 \\
\hline IVTA to pIC & $76.27 \pm 91.95$ & $59.45 \pm 68.97$ & $46.88 \pm 58.16$ & 1.251 & 0.292 \\
\hline IVTA to vaIC & $17.21 \pm 27.71$ & $8.95 \pm 3.49$ & $16.54 \pm 17.90$ & 0.763 & 0.470 \\
\hline rNAcc to daIC & $11.09 \pm 44.34$ & $12.36 \pm 14.58$ & $7.99 \pm 16.06$ & 0.088 & 0.916 \\
\hline rNAcc to DLPFC & $18.54 \pm 26.02$ & $17.21 \pm 23.43$ & $31.69 \pm 59.31$ & 0.874 & 0.421 \\
\hline rNAcc to $1 \mathrm{OFC}$ & $449.74 \pm 512.68$ & $552.32 \pm 553.16$ & $583.00 \pm 575.02$ & 0.099 & 0.906 \\
\hline rNAcc to mOFC & $1352 \pm 943.98$ & $1660.94 \pm 1159.38$ & $2216.77 \pm 1315.54$ & 3.717 & 0.029 \\
\hline rNAcc to pIC & $129.18 \pm 244.89$ & $89.27 \pm 110.05$ & $80.98 \pm 92.41$ & 0.119 & 0.888 \\
\hline rNAcc to vaIC & $732.42 \pm 961.42$ & $1369.91 \pm 1410.50$ & $718.38 \pm 700.50$ & 2.082 & 0.132 \\
\hline rAmy to daIC & $8.39 \pm 11.46$ & $25.53 \pm 21.64$ & $7.82 \pm 9.24$ & 8.190 & 0.001 \\
\hline rAmy to DLPFC & $20.1 \pm 24.27$ & $18.14 \pm 9.89$ & $38.16 \pm 32.92$ & 4.356 & 0.016 \\
\hline rAmy to $1 \mathrm{OFC}$ & $95.41 \pm 101.87$ & $59.48 \pm 39.84$ & $129.18 \pm 107.97$ & 1.436 & 0.244 \\
\hline rAmy to mOFC & $1246.66 \pm 1069.13$ & $937.87 \pm 852.42$ & $1075.12 \pm 992.10$ & 0.389 & 0.679 \\
\hline rAmy to pIC & $77.06 \pm 144.08$ & $118.83 \pm 138.32$ & $70.62 \pm 80.30$ & 0.985 & 0.378 \\
\hline rAmy to vaIC & $736.59 \pm 824.11$ & $818.15 \pm 756.58$ & $631.73 \pm 508.82$ & 0.502 & 0.607 \\
\hline rVTA to daIC & $23.3 \pm 40.78$ & $17.45 \pm 28.28$ & $35.64 \pm 59.95$ & 0.683 & 0.508 \\
\hline rVTA to DLPFC & $122.45 \pm 94.52$ & $77.53 \pm 68.19$ & $148.46 \pm 124.59$ & 2.100 & 0.130 \\
\hline rVTA to $1 \mathrm{OFC}$ & $149.33 \pm 169.72$ & $64.63 \pm 82.54$ & $134.87 \pm 151.53$ & 1.262 & 0.289 \\
\hline rVTA to mOFC & $67.24 \pm 93.39$ & $26.85 \pm 29.73$ & $52.22 \pm 91.28$ & 0.656 & 0.522 \\
\hline rVTA to pIC & $14.77 \pm 17.26$ & $30.91 \pm 69.09$ & $14.17 \pm 18.00$ & 1.283 & 0.283 \\
\hline rVTA to vaIC & $10.68 \pm 11.90$ & $13.23 \pm 17.42$ & $17.54 \pm 18.96$ & 0.543 & 0.583 \\
\hline
\end{tabular}

Amy: amygdala; CI: connectivity index; daIC: dorsal-anterior insular cortex; DLPFC: dorso-lateral prefrontal cortex; HCs: healthy controls; 1: left; lOFC: lateral orbito-frontal cortex; mOFC: medial orbito-frontal cortex; Nacc: nucleus accumbens; pIC: posterior insular cortex; r: right; SCZ: subjects with schizophrenia; vaIC: ventral-anterior insular cortex; VTA: ventral tegmental area. $p<0.0014$ was used as statistical threshold; $p$ values in boldface indicate statistical significance corrected for multiple tests; Bonferroni's post-hoc bivariate test: CI rAmy to daIC: DS-NDS, $p=0.001$; DS-HCs, $p=0.001$. 


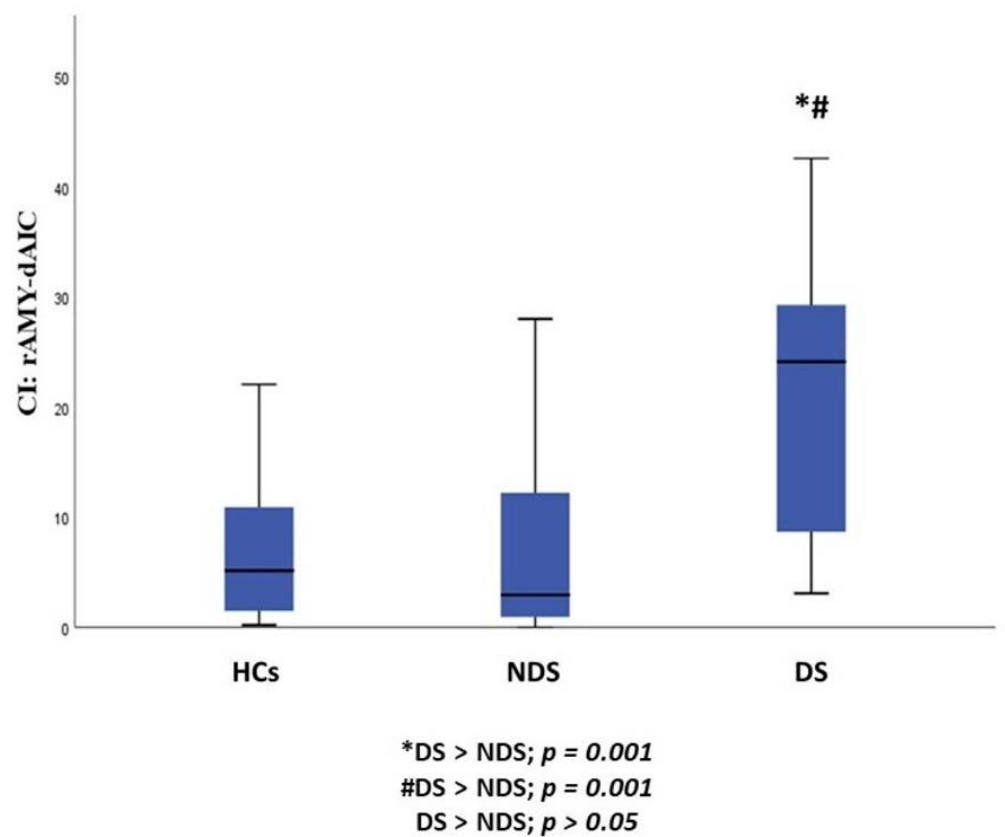

Figure 2. Group differences between DS, NDS and HCs in the CI of the rAmy-daIC pathway. HCs: healthy controls; DS: subjects with deficit schizophrenia; NDS: subjects with non-deficit schizophrenia CI: connectivity index; rAmy: right amygdala; daIC: dorsal-anterior insular cortex.

Furthermore, a statistically significant difference between DS, NDS and HCs was observed in FA of the INAcc-pIC pathway $(p=0.001)$. Post hoc pairwise comparisons demonstrated an increase in FA of the INAcc-pIC pathway in DS compared to both NDS $(p=0.001)$ and HCs $(p<0.001)$, while no differences were found between NDS and HCs (Table 3, Figure 3).

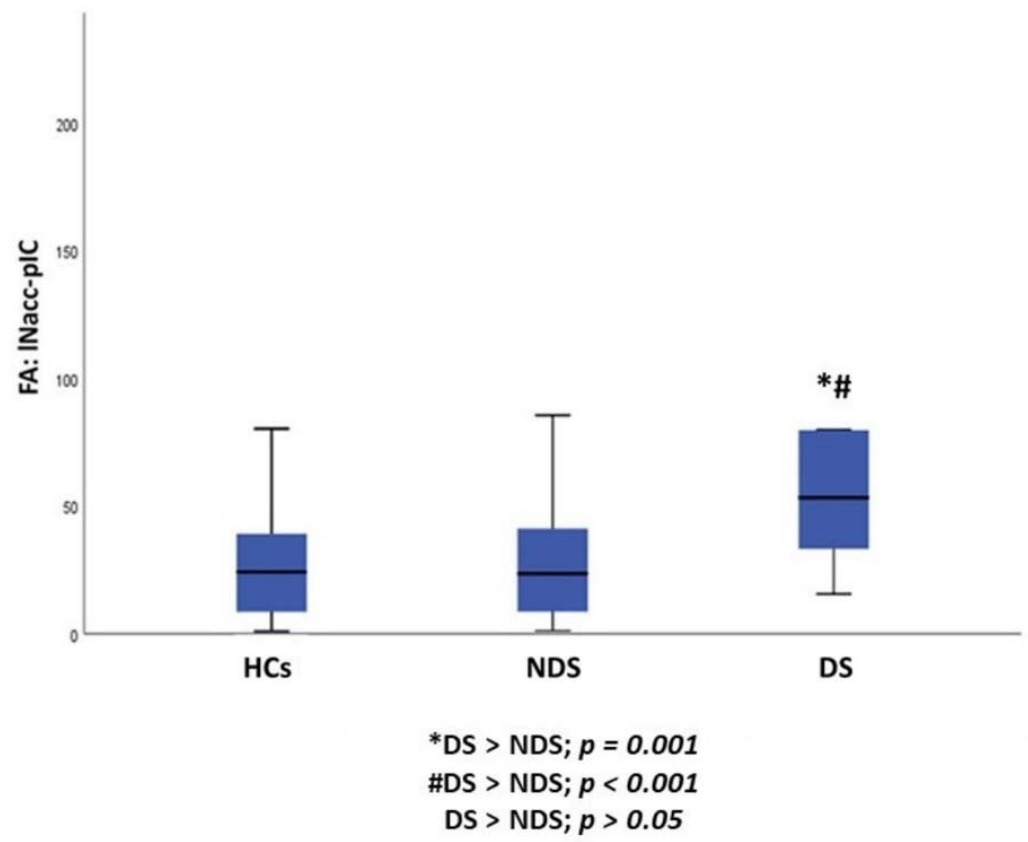

Figure 3. Group differences between DS, NDS and HCs in the FA of the INAcc-pIC pathway. HCs: healthy controls; DS: subjects with deficit schizophrenia; NDS: subjects with non-deficit schizophrenia FA: fractional anisotropy; 1NAcc: left nucleus accumbens; pIC: posterior insular cortex. 
Table 3. Group differences between DS, NDS and HCs in FA.

\begin{tabular}{|c|c|c|c|c|c|}
\hline Brain Pathways & NDS $(n=37)$ & DS $(n=9)$ & HCs $(n=35)$ & $\mathbf{F}$ & $p$ \\
\hline \multicolumn{6}{|c|}{ FA } \\
\hline INAcc to daIC & $1.54 \pm 1.27$ & $1.26 \pm 0.81$ & $1.60 \pm 1.20$ & 0.273 & 0.762 \\
\hline INAcc to DLPFC & $3.35 \pm 3.76$ & $1.69 \pm 1.25$ & $3.27 \pm 3.55$ & 0.967 & 0.385 \\
\hline INAcc to $1 \mathrm{OFC}$ & $7.14 \pm 10.8$ & $6.45 \pm 4.54$ & $7.32 \pm 7.66$ & 0.081 & 0.923 \\
\hline INAcc to $\mathrm{mOFC}$ & $49.93 \pm 29.7$ & $61.72 \pm 41.81$ & $63.01 \pm 46.42$ & 0.857 & 0.429 \\
\hline INAcc to pIC & $31.77 \pm 27.32$ & $76.48 \pm 68.31$ & $28.20 \pm 22.57$ & 7.760 & 0.001 \\
\hline INAcc to vaIC & $27.45 \pm 22.09$ & $52.3 \pm 39.84$ & $29.48 \pm 20.19$ & 4.202 & 0.019 \\
\hline 1Amy to daIC & $6.85 \pm 5.22$ & $4.01 \pm 1.93$ & $6.78 \pm 5.80$ & 1.645 & 0.200 \\
\hline 1Amy to DLPFC & $1047.97 \pm 167.3$ & $1099.55 \pm 207$ & $1030.49 \pm 232.41$ & 0.347 & 0.708 \\
\hline lAmy to $1 \mathrm{OFC}$ & $0.99 \pm 1.36$ & $0.57 \pm 0.32$ & $0.86 \pm 0.91$ & 0.792 & 0.457 \\
\hline 1Amy to mOFC & $12.80 \pm 17.30$ & $5.14 \pm 5.73$ & $6.74 \pm 9.25$ & 0.935 & 0.397 \\
\hline 1Amy to pIC & $51.63 \pm 36.29$ & $74.7 \pm 31.73$ & $45.06 \pm 27.15$ & 3.351 & 0.040 \\
\hline 1Amy to vaIC & $43.46 \pm 17.84$ & $43.71 \pm 14.56$ & $51.67 \pm 22.79$ & 2.098 & 0.130 \\
\hline IVTA to daIC & $5.00 \pm 5.80$ & $2.11 \pm 0.71$ & $4.12 \pm 3.99$ & 1.079 & 0.345 \\
\hline IVTA to DLPFC & $8.29 \pm 8.86$ & $5.84 \pm 5.69$ & $8.36 \pm 4.55$ & 0.848 & 0.432 \\
\hline IVTA to $1 \mathrm{OFC}$ & $8.53 \pm 6.07$ & $5.16 \pm 4.09$ & $10.04 \pm 8.15$ & 1.982 & 0.145 \\
\hline IVTA to $\mathrm{mOFC}$ & $6.11 \pm 4.86$ & $5.24 \pm 5.8$ & $8.04 \pm 6.98$ & 1.967 & 0.147 \\
\hline IVTA to pIC & $5.99 \pm 5.42$ & $4.66 \pm 3.48$ & $3.76 \pm 3.35$ & 2.324 & 0.105 \\
\hline IVTA to vaIC & $1.96 \pm 1.45$ & $1.62 \pm 0.5$ & $2.01 \pm 1.12$ & 0.389 & 0.679 \\
\hline rNAcc to daIC & $1.58 \pm 3.42$ & $2.13 \pm 1.72$ & $1.14 \pm 0.94$ & 0.540 & 0.585 \\
\hline rNAcc to DLPFC & $2.20 \pm 2.93$ & $1.67 \pm 1.47$ & $2.82 \pm 4.03$ & 0.454 & 0.637 \\
\hline rNAcc to $1 \mathrm{OFC}$ & $20.76 \pm 21.26$ & $24.71 \pm 25.40$ & $24.17 \pm 20.67$ & 0.019 & 0.981 \\
\hline rNAcc to mOFC & $55.36 \pm 42.34$ & $65.68 \pm 44.25$ & $81.19 \pm 54.45$ & 1.465 & 0.238 \\
\hline rNAcc to pIC & $9.65 \pm 14.76$ & $7.84 \pm 8.17$ & $7.32 \pm 6.61$ & 0.065 & 0.937 \\
\hline rNAcc to vaIC & $33.99 \pm 34.61$ & $50.40 \pm 39.62$ & $26.54 \pm 19.49$ & 2.392 & 0.098 \\
\hline rAmy to daIC & $2.00 \pm 1.75$ & $3.99 \pm 2.16$ & $1.85 \pm 1.24$ & 6.792 & 0.002 \\
\hline rAmy to DLPFC & $17.86 \pm 10.45$ & $13.17 \pm 10.71$ & $15.21 \pm 11.37$ & 0.788 & 0.459 \\
\hline rAmy to $1 \mathrm{OFC}$ & $1.43 \pm 1.53$ & $0.65 \pm 0.48$ & $1.72 \pm 2.99$ & 1.692 & 0.191 \\
\hline rAmy to mOFC & $8.49 \pm 8.26$ & $7.91 \pm 7.39$ & $9.39 \pm 9.86$ & 0.114 & 0.892 \\
\hline rAmy to pIC & $8.07 \pm 11.83$ & $9.18 \pm 6.32$ & $7.21 \pm 5.35$ & 0.366 & 0.695 \\
\hline rAmy to vaIC & $17.07 \pm 11.95$ & $20.13 \pm 14.73$ & $13.61 \pm 7.93$ & 1.740 & 0.183 \\
\hline rVTA to daIC & $3.75 \pm 7.44$ & $2.73 \pm 2.9$ & $3.97 \pm 4.86$ & 0.214 & 0.808 \\
\hline rVTA to DLPFC & $8.49 \pm 5.63$ & $5.57 \pm 4.14$ & $8.44 \pm 5.63$ & 1.222 & 0.300 \\
\hline rVTA to $1 \mathrm{OFC}$ & $12.23 \pm 11.34$ & $6.27 \pm 7.3$ & $9.24 \pm 8.24$ & 1.782 & 0.175 \\
\hline rVTA to mOFC & $6.81 \pm 5.86$ & $3.36 \pm 3.49$ & $5.17 \pm 8.93$ & 0.750 & 0.476 \\
\hline rVTA to pIC & $1.88 \pm 1.54$ & $2.99 \pm 4.41$ & $1.76 \pm 1.26$ & 1.437 & 0.244 \\
\hline rVTA to vaIC & $1.66 \pm 1.13$ & $1.95 \pm 1.64$ & $2.10 \pm 1.38$ & 0.357 & 0.701 \\
\hline
\end{tabular}

Amy: amygdala; daIC: dorsal-anterior insular cortex; DLPFC: dorso-lateral prefrontal cortex; FA: fractional anisotropy; HCs: healthy controls; 1: left; lOFC: lateral orbito-frontal cortex; mOFC: medial orbito-frontal cortex; Nacc: nucleus accumbens; pIC: posterior insular cortex; r: right; SCZ: subjects with schizophrenia; vaIC: ventralanterior insular cortex; VTA: ventral tegmental area. $p<0.0014$ was used as statistical threshold; $p$ values in boldface indicate statistical significance corrected for multiple tests; Bonferroni's post-hoc bivariate test: FA INAcc to $\mathrm{pIC}$ : DS-NDS, $p=0.001$; DS-HCs, $p<0.001$. 
Finally, the three groups differed at a trend level in the CI and FA of different pathways (Table 2). However, these results did not survive correction for multiple tests.

\section{Discussion}

In this study, we carried out a probabilistic DTI analysis to explore abnormalities in structural connectivity within motivational circuits in subjects with schizophrenia, differentiating patients with DS and NDS.

We found that all subjects with schizophrenia had a reduced CI between rAmy and homolateral DLPFC; however, this result did not survive correction for multiple tests. The altered connectivity within this circuit suggests that subjects with schizophrenia have an impairment in the integration of motivational and cognitive information for goal-directed behavior $[4,39]$. It is possible that the heterogeneity within the syndrome might obscure findings concerning connectivity indices within the motivational circuit.

Considering the three sample groups (DS, NDS and HCs), we found that, DS, as compared to NDS and HCs, showed 1) a significant increase in CI in the rAmy-daIC pathway and 2) a significant increase in FA of the INAcc-pIC pathway.

According to our findings, only subjects with DS showed abnormalities in the neural pathways involving mainly the Amy, the IC and the NAcc.

Firstly, DS, in comparison to NDS and HCs, showed an increase in CI between the rAmy and the daIC. Although at a trend level, the FA of the same pathway was also increased in DS, as compared to NDS and HCs. Therefore, DS showed abnormal connectivity strength (indicated by an increased CI) and disturbed fiber integrity (indicated by an increased FA) between the amygdala and dorsal-anterior insular cortex, probably suggesting an altered pruning process [99]. Pathways connecting the amygdala and insular cortex play a critical role in modulating and mediating connections between the two motivational systems [4] and are involved in upgrading and recalling the value information to support goal-directed behavior $[100,101]$. In particular, the amygdala, which seems to act in close collaboration with the OFC [102-105] and the ventral and medial areas of the prefrontal cortex and ventral striatum [106,107], plays a key role in reward processing and in stimulusreward associations [108-112]. It is involved in the stimulus-response association and in orienting attention towards salient stimuli, which suggests its usefulness in evaluating the environmental context [62].

As regards the daIC, several studies have suggested that this brain region plays a key role in salience processing [113] and also modulates cognitive flexibility and autonomic activation in response to environmental changes with a general recruitment of attention, executive and working memory resources [114].

Furthermore, in our work, we observed abnormalities in fiber integrity, as suggested by the increase in FA for pathways connecting the INAcc with pIC in DS, not present in NDS and in HCs. NAcc plays a critical role in transferring information from the IC to the "associative" medial DSr and the "sensorimotor" lateral one, connected to the cortical executive circuit, to influence motivated behavior.

In addition, previous findings indicated that the NAcc-IC pathway is strongly interconnected with the social decision-making network [115], thus playing a critical role in social behaviors-for instance, social cognition, which is often impaired in subjects with schizophrenia [49,116-118]. The IC is a site of multisensory integration [119-121] that provides an important cortical input to the NAcc, involved in reward [122,123]. Abnormalities in pathways connecting the INAcc with pIC in DS observed in our study might be interpreted in light of the presence in DS of a greater impairment of social cognition, in comparison with NDS and HCs [21-30].

Overall, our results could be interpreted in light of previous observations in animal studies. For instance, as has been demonstrated in rodents, the connections of IC with the basolateral amygdala (BLA) and NAcc within the motivational pathways are involved in the dynamic adjustment of behavior with respect to changes in outcome valuation, depending on the current motivational state (e.g., reduced motivation to look for a drink 
when not thirsty), an important aspect of motivation to engage in goal-directed behavior. BLA and IC give rise to a circuit in which BLA encodes and upgrades changes in outcome value, while IC, due to its connections with the NAcc, plays a key role in retrieving the encoded changes in outcome values to direct choices between motivated actions $[100,101]$. Therefore, our findings seem to highlight that a dysfunction within the motivational salience circuit and impaired connections between brain regions (Amy and IC) that serve as an interface between the two motivational circuits are fundamental aspects of DS. The structural hyperconnectivity found in these subjects might be interpreted as an altered pruning process in cerebral regions devoted to updating the value that a stimulus has for a subject to support goal-directed behavior [4,39,40,99].

Our study has several strengths. Indeed, previous studies that investigated WM alterations in DS did not search for abnormalities of motivational circuits, since this was not the primary objective of these studies [4,39,40,75-80]. Furthermore, in our study, the assessment of deficit schizophrenia was made using the SDS, which is regarded as the goldstandard instrument in this field. In some of the previously mentioned studies $[77,79,80]$, deficit schizophrenia was assessed using a proxy derived from the PANSS. The latter method for categorizing patients as DS and NDS has some problems in terms of face validity and temporal stability [14].

Structural connectivity analysis, which is used in this study, is not affected by poor general intellectual abilities or memory impairment, often present in subjects with schizophrenia, as subjects do not have to perform a task.

Our findings should be also interpreted in light of some limitations. First, the sample size is relatively small, which limits the possibility of generalizing the results. The small number of DS included in the analysis could prevent the detection of significant results. Further studies with larger samples, including a higher number of DS, are needed. In addition, the use of the SDS has prevented the evaluation of the severity of negative symptoms and testing of its association with structural connectivity parameters. Indeed, the SDS was developed to categorize subjects with schizophrenia as DS and NDS, and it is not appropriate to use the scale to evaluate symptom severity. Moreover, the use of the SDS might explain why, in our study, DS did not differ from NDS in terms of negative symptom severity, since other factors are considered to differentiate DS and NDS-for instance, the distinction between primary vs. secondary negative symptoms and transient vs. enduring negative symptoms. Future studies, using both SDS and an instrument for the evaluation of negative symptom severity, are needed to test the association between the impairment in motivational circuits in DS and negative symptom severity, as well as the possible differential associations with the two negative symptom domains.

Finally, DS and NDS differed in terms of depression scores, which we could not use as a covariate in the main analysis since we did not evaluate depression in the group of healthy controls. However, we should take into account that DS, which had lower depression scores than NDS, differed in terms of structural connectivity parameters from HCs and NDS, while no difference was found between NDS and HCs. Finally, the scores of depression were very low in both patient groups, as DS had a minimal level of depression and NDS a mild level of depression, far below the threshold of clinical significance.

In conclusion, our results lend support to the hypothesis of the presence of alterations in the motivational circuits as possible pathophysiological mechanisms of negative symptoms in subjects with schizophrenia. In addition, our data support previous evidence of distinct neurobiological alterations underlying the different clinical subtypes of schizophrenia. In particular, subjects with deficit schizophrenia, as compared to those with non-deficit schizophrenia and to healthy controls, probably present an altered pruning process (consistent with the hyperconnectivity) in cerebral regions devoted to updating the value that a stimulus has for a subject in order to support goal-directed behavior.

Supplementary Materials: The following are available online at https: / www.mdpi.com/article/ 10.3390/jcm11010061/s1, Table S1. Demographic characteristics, RMS and illness related variables; Table S2. Group differences between SCZ and HCs in CI; Table S3. Group differences between SCZ 
and HCs in FA. Figure S1. 3D representation of the average distribution of the connection patterns between the right amygdala and the ipsilateral dorso-lateral prefrontal cortex; Figure S2. Group differences between SCZ and HCs in the CI of the pathway connecting right amygdala and the ipsilateral dorsolateral prefrontal cortex.

Author Contributions: Conceptualization, G.M.G., P.P., M.Q., P.B., A.P. (Anna Prinster) A.S., A.P. (Andrea Perrottelli), L.G., M.F. and S.G.; Methodology, G.M.G., P.P., M.Q., P.B., A.P. (Anna Prinster), A.S., A.P. (Andrea Perrottelli), L.G., M.F. and S.G.; Project administration, G.M.G., P.B. and S.G.; Supervision, P.B. and S.G.; Writing-original draft, G.M.G., P.P., M.Q., P.B., A.P. (Anna Prinster), A.S., A.P. (Andrea Perrottelli), L.G., M.F. and S.G.; Writing-review and editing, G.M.G., P.P., M.Q., P.B., A.P. (Anna Prinster), A.S., A.P. (Andrea Perrottelli), L.G., M.F. and S.G. All authors were responsible for the interpretation of the analyses, contributed to critically revising the content and approved the final manuscript for submission to the Journal of Clinical Medicine. All authors have read and agreed to the published version of the manuscript.

Funding: The author(s) declare that Compagnia di San Paolo, Turin, Italy, partially funded this study within the project 'Reward system and primary negative symptoms in schizophrenia' (Grant No.: 2008.24011).

Institutional Review Board Statement: The study was performed in accordance with the ethical principles of the Declaration of Helsinki and approved by the Ethics Committee of the Seconda Università degli Studi di Napoli-A.O.U. "Seconda Università degli Studi di Napoli", A.O.R.N. “Ospedali dei Colli" (protocol code 126, 1 July 2010).

Informed Consent Statement: All participants gave written informed consent after a detailed description of the study procedures and goals.

Data Availability Statement: All data supporting the findings of this study are available within the article and Supplementary Materials.

Conflicts of Interest: The authors declare no conflict of interest.

\section{References}

1. Kraepelin, E. Dementia Praecox and Paraphrenia; Chicago Medical Book: Chicago, IL, USA, 1919.

2. Bleuler, E. Dementia Praecox or the Group of Schizophrenias; International Universities Press: New York, NY, USA, 1950.

3. Foussias, G.; Agid, O.; Fervaha, G.; Remington, G. Negative symptoms of schizophrenia: Clinical features, relevance to real world functioning and specificity versus other CNS disorders. Eur. Neuropsychopharmacol. 2014, 24, 693-709. [CrossRef]

4. Galderisi, S.; Mucci, A.; Buchanan, R.W.; Arango, C. Negative symptoms of schizophrenia: New developments and unanswered research questions. Lancet Psychiatry 2018, 5, 664-677. [CrossRef]

5. Sahakian, B.; Savulich, G. Innovative methods for improving cognition, motivation and wellbeing in schizophrenia. World Psychiatry 2019, 18, 168-170. [CrossRef]

6. Falkai, P.; Schmitt, A. The need to develop personalized interventions to improve cognition in schizophrenia. World Psychiatry 2019, 18, 170. [CrossRef]

7. Harvey, P.D.; Strassnig, M.T. Cognition and disability in schizophrenia: Cognition-related skills deficits and decision-making challenges add to morbidity. World Psychiatry 2019, 18, 165-167. [CrossRef]

8. Keefe, R.S. Why are there no approved treatments for cognitive impairment in schizophrenia? World Psychiatry 2019, 18, 167-168. [CrossRef] [PubMed]

9. Reichenberg, A.; Velthorst, E.; Davidson, M. Cognitive impairment and psychosis in schizophrenia: Independent or linked conditions? World Psychiatry 2019, 18, 162-163. [CrossRef] [PubMed]

10. Correll, C.U.; Schooler, N.R. Negative Symptoms in Schizophrenia: A Review and Clinical Guide for Recognition, Assessment, and Treatment. Neuropsychiatr. Dis. Treat. 2020, 16, 519-534. [CrossRef] [PubMed]

11. Galderisi, S.; Rucci, P.; Mucci, A.; Rossi, A.; Rocca, P.; Bertolino, A.; Aguglia, E.; Amore, M.; Bellomo, A.; Bozzatello, P.; et al. The interplay among psychopathology, personal resources, context-related factors and real-life functioning in schizophrenia: Stability in relationships after 4 years and differences in network structure between recovered and non-recovered patients. World Psychiatry 2020, 19, 81-91. [CrossRef]

12. Heckers, S.; Kendler, K.S. The evolution of Kraepelin's nosological principles. World Psychiatry 2020, 19, 381-388. [CrossRef]

13. Galderisi, S.; Kaiser, S.; Bitter, I.; Nordentoft, M.; Mucci, A.; Sabé, M.; Giordano, G.M.; Nielsen, M.; Glenthøj, L.B.; Pezzella, P.; et al. EPA guidance on treatment of negative symptoms in schizophrenia. Eur. Psychiatry 2021, 64, e21. [CrossRef]

14. Galderisi, S.; Mucci, A.; Dollfus, S.; Nordentoft, M.; Falkai, P.; Kaiser, S.; Giordano, G.M.; Vandevelde, A.; Nielsen, M.; Glenthøj, L.B.; et al. EPA guidance on assessment of negative symptoms in schizophrenia. Eur. Psychiatry 2021, 64, 1-91. [CrossRef] 
15. Kirkpatrick, B.; Fenton, W.S.; Carpenter, W.T.; Marder, S.R. The NIMH-MATRICS Consensus Statement on Negative Symptoms. Schizophr. Bull. 2006, 32, 214-219. [CrossRef]

16. Marder, S.R.; Galderisi, S. The current conceptualization of negative symptoms in schizophrenia. World Psychiatry 2017, 16, 14-24. [CrossRef]

17. Reed, G.M.; First, M.B.; Kogan, C.S.; Hyman, S.E.; Gureje, O.; Gaebel, W.; Maj, M.; Stein, D.; Maercker, A.; Tyrer, P.; et al. Innovations and changes in the ICD-11 classification of mental, behavioural and neurodevelopmental disorders. World Psychiatry 2019, 18, 3-19. [CrossRef] [PubMed]

18. Gaebel, W.; Falkai, P.; Hasan, A. The revised German evidence- and consensus-based schizophrenia guideline. World Psychiatry 2020, 19, 117-119. [CrossRef]

19. Giordano, G.M.; Koenig, T.; Mucci, A.; Vignapiano, A.; Amodio, A.; di Lorenzo, G.; Siracusano, A.; Bellomo, A.; Altamura, M.; Monteleone, P.; et al. Neurophysiological correlates of Avolition-apathy in schizophrenia: A resting-EEG microstates study. NeuroImage Clin. 2018, 20, 627-636. [CrossRef] [PubMed]

20. Giordano, G.M.; Brando, F.; Perrottelli, A.; Di Lorenzo, G.; Siracusano, A.; Giuliani, L.; Pezzella, P.; Altamura, M.; Bellomo, A.; Cascino, G.; et al. Tracing links between early auditory information processing and negative symptoms in schizophrenia: An ERP study. Front. Psychiatry, 2021; in press.

21. Galderisi, S.; Maj, M.; Mucci, A.; Cassano, G.B.; Invernizzi, G.; Rossi, A.; Vita, A.; Dell'Osso, L.; Daneluzzo, E.; Pini, S. Historical, Psychopathological, Neurological, and Neuropsychological Aspects of Deficit Schizophrenia: A Multicenter Study. Am. J. Psychiatry 2002, 159, 983-990. [CrossRef]

22. Buchanan, R.W. Persistent Negative Symptoms in Schizophrenia: An Overview. Schizophr. Bull. 2007, 33, 1013-1022. [CrossRef]

23. Kirkpatrick, B.; Galderisi, S. Deficit schizophrenia: An update. World Psychiatry 2008, 7, 143-147. [CrossRef]

24. Galderisi, S.; Maj, M. Deficit schizophrenia: An overview of clinical, biological and treatment aspects. Eur. Psychiatry 2009, 24, 493-500. [CrossRef]

25. Kirkpatrick, B. Progress in the Study of Negative Symptoms. Schizophr. Bull. 2014, 40, S101-S106. [CrossRef] [PubMed]

26. Kirkpatrick, B. Recognizing Primary vs. Secondary Negative Symptoms and Apathy vs. Expression Domains. J. Clin. Psychiatry 2014, 75, e09. [CrossRef]

27. Galderisi, S.; Merlotti, E.; Mucci, A. Neurobiological background of negative symptoms. Eur. Arch. Psychiatry Clin. Neurosci. 2015, 265, 543-558. [CrossRef] [PubMed]

28. Mucci, A.; Merlotti, E.; Üçok, A.; Aleman, A.; Galderisi, S. Primary and persistent negative symptoms: Concepts, assessments and neurobiological bases. Schizophr. Res. 2016, 186, 19-28. [CrossRef] [PubMed]

29. Bucci, P.; Galderisi, S. Categorizing and assessing negative symptoms. Curr. Opin. Psychiatry 2017, 30, 201-208. [CrossRef]

30. Kirkpatrick, B.; Mucci, A.; Galderisi, S. Primary, Enduring Negative Symptoms: An Update on Research. Schizophr. Bull. 2017, 43, 730-736. [CrossRef]

31. Barch, D.M.; Dowd, E.C. Goal Representations and Motivational Drive in Schizophrenia: The Role of Prefrontal-Striatal Interactions. Schizophr. Bull. 2010, 36, 919-934. [CrossRef]

32. Foussias, G.; Remington, G. Negative Symptoms in Schizophrenia: Avolition and Occam's Razor. Schizophr. Bull. 2008, 36, 359-369. [CrossRef]

33. Bromberg-Martin, E.S.; Matsumoto, M.; Hikosaka, O. Dopamine in Motivational Control: Rewarding, Aversive, and Alerting. Neuron 2010, 68, 815-834. [CrossRef]

34. Simpson, E.H.; Waltz, J.A.; Kellendonk, C.; Balsam, P.D. Schizophrenia in Translation: Dissecting Motivation in Schizophrenia and Rodents. Schizophr. Bull. 2012, 38, 1111-1117. [CrossRef] [PubMed]

35. Strauss, G.P.; Horan, W.P.; Kirkpatrick, B.; Fischer, B.A.; Keller, W.R.; Miski, P.; Buchanan, R.W.; Green, M.F.; Carpenter, W.T. Deconstructing negative symptoms of schizophrenia: Avolition-apathy and diminished expression clusters predict clinical presentation and functional outcome. J. Psychiatr. Res. 2013, 47, 783-790. [CrossRef] [PubMed]

36. Morris, R.; Quail, S.; Griffiths, K.R.; Green, M.; Balleine, B.W. Corticostriatal Control of Goal-Directed Action Is Impaired in Schizophrenia. Biol. Psychiatry 2015, 77, 187-195. [CrossRef] [PubMed]

37. Mucci, A.; Dima, D.; Soricelli, A.; Volpe, U.; Bucci, P.; Frangou, S.; Prinster, A.; Salvatore, M.; Galderisi, S.; Maj, M. Is avolition in schizophrenia associated with a deficit of dorsal caudate activity? A functional magnetic resonance imaging study during reward anticipation and feedback. Psychol. Med. 2015, 45, 1765-1778. [CrossRef] [PubMed]

38. Salamone, J.D.; Yohn, S.E.; Lopez-Cruz, L.; Miguel, N.S.; Correa, M. Activational and effort-related aspects of motivation: Neural mechanisms and implications for psychopathology. Brain 2016, 139, 1325-1347. [CrossRef]

39. Giordano, G.M.; Stanziano, M.; Papa, M.; Mucci, A.; Prinster, A.; Soricelli, A.; Galderisi, S. Functional connectivity of the ventral tegmental area and avolition in subjects with schizophrenia: A resting state functional MRI study. Eur. Neuropsychopharmacol. 2018, 28, 589-602. [CrossRef]

40. Amodio, A.; Quarantelli, M.; Mucci, A.; Prinster, A.; Soricelli, A.; Vignapiano, A.; Giordano, G.M.; Merlotti, E.; Nicita, A.; Galderisi, S. Avolition-Apathy and White Matter Connectivity in Schizophrenia: Reduced Fractional Anisotropy between Amygdala and Insular Cortex. Clin. EEG Neurosci. 2017, 49, 55-65. [CrossRef]

41. Sanislow, C.A. RDoC at 10: Changing the discourse for psychopathology. World Psychiatry 2020, 19, 311-312. [CrossRef]

42. Menon, V. Brain networks and cognitive impairment in psychiatric disorders. World Psychiatry 2020, 19, 309-310. [CrossRef] 
43. Barch, D.M.; Pagliaccio, D.; Luking, K. Mechanisms Underlying Motivational Deficits in Psychopathology: Similarities and Differences in Depression and Schizophrenia. Curr Top. Behav. Neurosci. 2016, 27, 411-449. [CrossRef]

44. Striatal dopamine, reward, and decision making in schizophrenia. Dialog. Clin. Neurosci. 2016, 18, 77-89. [CrossRef]

45. Green, M.F.; Horan, W.P.; Barch, D.M.; Gold, J.M. Effort-Based Decision Making: A Novel Approach for Assessing Motivation in Schizophrenia. Schizophr. Bull. 2015, 41, 1035-1044. [CrossRef]

46. Mucci, A.; Galderisi, S.; Green, M.F.; Nuechterlein, K.; Rucci, P.; Gibertoni, D.; Rossi, A.; Rocca, P.; Bertolino, A.; Bucci, P.; et al. Familial aggregation of MATRICS Consensus Cognitive Battery scores in a large sample of outpatients with schizophrenia and their unaffected relatives. Psychol. Med. 2017, 48, 1359-1366. [CrossRef] [PubMed]

47. Davidson, M. Cognitive impairment as a diagnostic criterion and treatment target in schizophrenia. World Psychiatry 2019, 18, 171-172. [CrossRef] [PubMed]

48. Grant, P.M.; Best, M.W.; Beck, A.T. The meaning of group differences in cognitive test performance. World Psychiatry 2019, 18, 163-164. [CrossRef]

49. Green, M.F.; Horan, W.P.; Lee, J. Nonsocial and social cognition in schizophrenia: Current evidence and future directions. World Psychiatry 2019, 18, 146-161. [CrossRef]

50. Besteher, B.; Brambilla, P.; Nenadić, I. Twin studies of brain structure and cognition in schizophrenia. Neurosci. Biobehav. Rev. 2019, 109, 103-113. [CrossRef]

51. Moritz, S.; Silverstein, S.M.; Dietrichkeit, M.; Gallinat, J. Neurocognitive deficits in schizophrenia are likely to be less severe and less related to the disorder than previously thought. World Psychiatry 2020, 19, 254-255. [CrossRef]

52. Caputo, F.; Giordano, G.M.; Mucci, A.; Galderisi, S. Aetiopathological mechanisms of negative symptoms in schizophrenia. Die Psychiatr. 2016, 13, 121-129. [CrossRef]

53. Melle, I. Cognition in schizophrenia: A marker of underlying neurodevelopmental problems? World Psychiatry 2019, 18, 164-165. [CrossRef] [PubMed]

54. Miller, E.M.; Shankar, M.U.; Knutson, B.; McClure, S.M. Dissociating Motivation from Reward in Human Striatal Activity. J. Cogn. Neurosci. 2014, 26, 1075-1084. [CrossRef] [PubMed]

55. Bissonette, G.B.; Roesch, M.R. Development and function of the midbrain dopamine system: What we know and what we need to. Genes Brain Behav. 2015, 15, 62-73. [CrossRef]

56. Bissonette, G.B.; Roesch, M.R. Neurophysiology of Reward-Guided Behavior: Correlates Related to Predictions, Value, Motivation, Errors, Attention, and Action. Curr. Top. Behav. Neurosci. 2016, 27, 199-230. [CrossRef]

57. O'Doherty, J.P. Multiple Systems for the Motivational Control of Behavior and Associated Neural Substrates in Humans. Curr. Top. Behav. Neurosci. 2016, 27, 291-312. [CrossRef] [PubMed]

58. Cohen, A.; Schwartz, E.; Le, T.P.; Fedechko, T.; Kirkpatrick, B.; Strauss, G.P. Using biobehavioral technologies to effectively advance research on negative symptoms. World Psychiatry 2019, 18, 103-104. [CrossRef] [PubMed]

59. Bowie, C.R. Cognitive remediation for severe mental illness: State of the field and future directions. World Psychiatry 2019, 18, 274-275. [CrossRef]

60. Stefani, M.R. Rule Learning and Reward Contingency Are Associated with Dissociable Patterns of Dopamine Activation in the Rat Prefrontal Cortex, Nucleus Accumbens, and Dorsal Striatum. J. Neurosci. 2006, 26, 8810-8818. [CrossRef] [PubMed]

61. Hikosaka, O.; Bromberg-Martin, E.; Hong, S.; Matsumoto, M. New insights on the subcortical representation of reward. Curr. Opin. Neurobiol. 2008, 18, 203-208. [CrossRef] [PubMed]

62. Haber, S.N.; Knutson, B. The Reward Circuit: Linking Primate Anatomy and Human Imaging. Neuropsychopharmacology 2009, 35, 4-26. [CrossRef] [PubMed]

63. Sesack, S.R.; Grace, A.A. Cortico-Basal Ganglia Reward Network: Microcircuitry. Neuropsychopharmacology 2010, $35,27-47$. [CrossRef] [PubMed]

64. Cascella, N.G.; Fieldstone, S.C.; Rao, V.A.; Pearlson, G.D.; Sawa, A.; Schretlen, D.J. Gray-matter abnormalities in deficit schizophrenia. Schizophr. Res. 2010, 120, 63-70. [CrossRef]

65. Friston, K.J.; Frith, C.D. Schizophrenia: A disconnection syndrome? Clin. Neurosci. 1995, 3, 89-97. [PubMed]

66. Buchsbaum, M.S.; Tang, C.Y.; Peled, S.; Gudbjartsson, H.; Lu, D.; Hazlett, E.A.; Downhill, J.; Haznedar, M.; Fallon, J.H.; Atlas, S.W. MRI white matter diffusion anisotropy and PET metabolic rate in schizophrenia. NeuroReport 1998, 9, 425-430. [CrossRef]

67. Lim, K.O.; Hedehus, M.; Moseley, M.; de Crespigny, A.; Sullivan, E.V.; Pfefferbaum, A. Compromised White Matter Tract Integrity in Schizophrenia Inferred from Diffusion Tensor Imaging. Arch. Gen. Psychiatry 1999, 56, 367-374. [CrossRef] [PubMed]

68. Ardekani, B.A.; Nierenberg, J.; Hoptman, M.J.; Javitt, D.C.; Lim, K.O. MRI study of white matter diffusion anisotropy in schizophrenia. NeuroReport 2003, 14, 2025-2029. [CrossRef]

69. Hoptman, M.J.; D’Angelo, D.; Catalano, D.; Mauro, C.J.; Shehzad, Z.E.; Kelly, A.M.C.; Castellanos, F.X.; Javitt, D.C.; Milham, M.P. Amygdalofrontal Functional Disconnectivity and Aggression in Schizophrenia. Schizophr. Bull. 2009, 36, 1020-1028. [CrossRef]

70. Pettersson-Yeo, W.; Allen, P.; Benetti, S.; McGuire, P.; Mechelli, A. Dysconnectivity in schizophrenia: Where are we now? Neurosci. Biobehav. Rev. 2011, 35, 1110-1124. [CrossRef]

71. Kelly, S.; Jahanshad, N.; Zalesky, A.; Kochunov, P.; Agartz, I.; Alloza, C.; Andreassen, O.A.; Arango, C.; Banaj, N.; Bouix, S.; et al. Widespread white matter microstructural differences in schizophrenia across 4322 individuals: Results from the ENIGMA Schizophrenia DTI Working Group. Mol. Psychiatry 2017, 23, 1261-1269. [CrossRef] 
72. Reininghaus, U.; Böhnke, J.R.; Chavez-Baldini, U.; Gibbons, R.; Ivleva, E.; Clementz, B.A.; Pearlson, G.D.; Keshavan, M.S.; Sweeney, J.A.; Tamminga, C.A. Transdiagnostic dimensions of psychosis in the Bipolar-Schizophrenia Network on Intermediate Phenotypes (B-SNIP). World Psychiatry 2019, 18, 67-76. [CrossRef] [PubMed]

73. Nath, M.; Wong, T.P.; Srivastava, L.K. Neurodevelopmental insights into circuit dysconnectivity in schizophrenia. Prog. NeuroPsychopharmacol. Biol. Psychiatry 2020, 104, 110047. [CrossRef]

74. Bullmore, E.; Frangou, S.; Murray, R. The dysplastic net hypothesis: An integration of developmental and dysconnectivity theories of schizophrenia. Schizophr. Res. 1997, 28, 143-156. [CrossRef]

75. Rowland, L.M.; Spieker, E.A.; Francis, A.; Barker, P.B.; Carpenter, W.T.; Buchanan, R.W. White Matter Alterations in Deficit Schizophrenia. Neuropsychopharmacology 2008, 34, 1514-1522. [CrossRef] [PubMed]

76. Kitis, O.; Ozalay, O.; Zengin, E.B.; Haznedaroglu, D.; Eker, M.C.; Yalvac, D.; Oguz, K.; Coburn, K.; Gonul, A.S. Reduced left uncinate fasciculus fractional anisotropy in deficit schizophrenia but not in non-deficit schizophrenia. Psychiatry Clin. Neurosci. 2012, 66, 34-43. [CrossRef] [PubMed]

77. Voineskos, A.N.; Foussias, G.; Lerch, J.; Felsky, D.; Remington, G.; Rajji, T.K.; Lobaugh, N.; Pollock, B.G.; Mulsant, B.H. Neuroimaging Evidence for the Deficit Subtype of Schizophrenia. JAMA Psychiatry 2013, 70, 472-480. [CrossRef] [PubMed]

78. Spalletta, G.; de Rossi, P.; Piras, F.; Iorio, M.; Dacquino, C.; Scanu, F.; Girardi, P.; Caltagirone, C.; Kirkpatrick, B.; Chiapponi, C. Brain white matter microstructure in deficit and non-deficit subtypes of schizophrenia. Psychiatry Res. Neuroimaging 2015, 231, 252-261. [CrossRef]

79. Tan, A.S.; Chew, Q.H.; Sim, K. Cerebral white matter changes in deficit and non-deficit subtypes of schizophrenia. J. Neural Transm. 2020, 127, 1073-1079. [CrossRef]

80. Podwalski, P.; Tyburski, E.; Szczygieł, K.; Waszczuk, K.; Rek-Owodziń, K.; Mak, M.; Plichta, P.; Bielecki, M.; Rudkowski, K.; Kucharska-Mazur, J.; et al. White Matter Integrity of the Corpus Callosum and Psychopathological Dimensions in Deficit and Non-Deficit Schizophrenia Patients. J. Clin. Med. 2021, 10, 2225. [CrossRef]

81. Kay, S.R.; Fiszbein, A.; Opler, L.A. The Positive and Negative Syndrome Scale (PANSS) for Schizophrenia. Schizophr. Bull. 1987, 13, 261-276. [CrossRef]

82. Fabrazzo, M.; Prisco, V.; Sampogna, G.; Perris, F.; Catapano, F.; Monteleone, A.M.; Maj, M. Clozapine versus other antipsychotics during the first 18 weeks of treatment: A retrospective study on risk factor increase of blood dyscrasias. Psychiatry Res. 2017, 256, 275-282. [CrossRef]

83. Kirkpatrick, B.; Buchanan, R.W.; McKenny, P.D.; Alphs, L.D.; Carpenter, W.T. The schedule for the deficit syndrome: An instrument for research in schizophrenia. Psychiatry Res. 1989, 30, 119-123. [CrossRef]

84. Gardner, D.M.; Murphy, A.L.; O'Donnell, H.; Centorrino, F.; Baldessarini, R.J. International Consensus Study of Antipsychotic Dosing. Am. J. Psychiatry 2010, 167, 686-693. [CrossRef] [PubMed]

85. Bracht, T.; Horn, H.; Strik, W.; Federspiel, A.; Razavi, N.; Stegmayer, K.; Wiest, R.; Dierks, T.; Müller, T.J.; Walther, S. White matter pathway organization of the reward system is related to positive and negative symptoms in schizophrenia. Schizophr. Res. 2014, 153, 136-142. [CrossRef] [PubMed]

86. Pizzagalli, D.A.; Holmes, A.; Dillon, D.G.; Goetz, E.L.; Birk, J.; Bogdan, R.; Dougherty, D.D.; Iosifescu, D.V.; Rauch, S.L.; Fava, M. Reduced Caudate and Nucleus Accumbens Response to Rewards in Unmedicated Individuals with Major Depressive Disorder. Am. J. Psychiatry 2009, 166, 702-710. [CrossRef] [PubMed]

87. Maldjian, J.A.; Laurienti, P.J.; Kraft, R.A.; Burdette, J.H. An automated method for neuroanatomic and cytoarchitectonic atlas-based interrogation of fMRI data sets. NeuroImage 2003, 19, 1233-1239. [CrossRef]

88. Blood, A.J.; Iosifescu, D.V.; Makris, N.; Perlis, R.H.; Kennedy, D.N.; Dougherty, D.D.; Kim, B.W.; Lee, M.J.; Wu, S.; Lee, S.H.; et al. Microstructural Abnormalities in Subcortical Reward Circuitry of Subjects with Major Depressive Disorder. PLoS ONE 2010, 5 , e13945. [CrossRef]

89. Nieuwenhuys, R.; Voogd, J.; van Huizen, C. The Human Central Nervous System, 4th ed.; Springer: Berlin, Germany, 2008.

90. Kringelbach, M.L. The human orbitofrontal cortex: Linking reward to hedonic experience. Nat. Rev. Neurosci. 2005, 6, 691-702. [CrossRef]

91. Makris, N.; Goldstein, J.M.; Kennedy, D.; Hodge, S.M.; Caviness, V.S.; Faraone, S.; Tsuang, M.T.; Seidman, L.J. Decreased volume of left and total anterior insular lobule in schizophrenia. Schizophr. Res. 2006, 83, 155-171. [CrossRef]

92. Deen, B.; Pitskel, N.B.; Pelphrey, K.A. Three Systems of Insular Functional Connectivity Identified with Cluster Analysis. Cereb. Cortex 2010, 21, 1498-1506. [CrossRef]

93. Smith, S.M.; Jenkinson, M.; Woolrich, M.W.; Beckmann, C.F.; Behrens, T.E.; Johansen-Berg, H.; Bannister, P.R.; de Luca, M.; Drobnjak, I.; Flitney, D.E.; et al. Advances in functional and structural MR image analysis and implementation as FSL. NeuroImage 2004, 23, S208-S219. [CrossRef]

94. Leemans, A.; Jones, D.K. TheB-matrix must be rotated when correcting for subject motion in DTI data. Magn. Reson. Med. 2009, 61, 1336-1349. [CrossRef]

95. Smith, S.M. Fast robust automated brain extraction. Hum. Brain Mapp. 2002, 17, 143-155. [CrossRef] [PubMed]

96. Smith, S.; Zhanga, Y.; Jenkinson, M.; Chenab, J.; Matthews, P.M.; Federico, A.; de Stefano, N. Accurate, Robust, and Automated Longitudinal and Cross-Sectional Brain Change Analysis. NeuroImage 2002, 17, 479-489. [CrossRef]

97. Behrens, T.; Johansen-Berg, H.; Jbabdi, S.; Rushworth, M.; Woolrich, M. Probabilistic diffusion tractography with multiple fibre orientations: What can we gain? NeuroImage 2007, 34, 144-155. [CrossRef] [PubMed] 
98. Morris, D.M.; Embleton, K.V.; Parker, G.J. Probabilistic fibre tracking: Differentiation of connections from chance events. NeuroImage 2008, 42, 1329-1339. [CrossRef] [PubMed]

99. Keshavan, M.; Lizano, P.; Prasad, K. The synaptic pruning hypothesis of schizophrenia: Promises and challenges. World Psychiatry 2020, 19, 110-111. [CrossRef]

100. Parkes, S.; Balleine, B.W. Incentive Memory: Evidence the Basolateral Amygdala Encodes and the Insular Cortex Retrieves Outcome Values to Guide Choice between Goal-Directed Actions. J. Neurosci. 2013, 33, 8753-8763. [CrossRef]

101. Parkes, S.; Bradfield, L.; Balleine, B.W. Interaction of Insular Cortex and Ventral Striatum Mediates the Effect of Incentive Memory on Choice between Goal-Directed Actions. J. Neurosci. 2015, 35, 6464-6471. [CrossRef] [PubMed]

102. Pickens, C.; Saddoris, M.P.; Setlow, B.; Gallagher, M.; Holland, P.C.; Schoenbaum, G. Different Roles for Orbitofrontal Cortex and Basolateral Amygdala in a Reinforcer Devaluation Task. J. Neurosci. 2003, 23, 11078-11084. [CrossRef]

103. Izquierdo, A.; Suda, R.K.; Murray, E. Bilateral Orbital Prefrontal Cortex Lesions in Rhesus Monkeys Disrupt Choices Guided by Both Reward Value and Reward Contingency. J. Neurosci. 2004, 24, 7540-7548. [CrossRef]

104. Ostlund, S.B.; Balleine, B. Orbitofrontal Cortex Mediates Outcome Encoding in Pavlovian but Not Instrumental Conditioning. J. Neurosci. 2007, 27, 4819-4825. [CrossRef] [PubMed]

105. Burke, K.A.; Franz, T.M.; Miller, D.N.; Schoenbaum, G. The role of the orbitofrontal cortex in the pursuit of happiness and more specific rewards. Nature 2008, 454, 340-344. [CrossRef] [PubMed]

106. Takahashi, Y.K.; Roesch, M.R.; Stalnaker, T.A.; Haney, R.Z.; Calu, D.; Taylor, A.R.; Burke, K.A.; Schoenbaum, G. The Orbitofrontal Cortex and Ventral Tegmental Area Are Necessary for Learning from Unexpected Outcomes. Neuron 2009, 62, 269-280. [CrossRef] [PubMed]

107. Kahnt, T.; Heinzle, J.; Park, S.; Haynes, J.-D. The neural code of reward anticipation in human orbitofrontal cortex. Proc. Natl. Acad. Sci. USA 2010, 107, 6010-6015. [CrossRef]

108. Everitt, B.; Cador, M.; Robbins, T. Interactions between the amygdala and ventral striatum in stimulus-reward associations: Studies using a second-order schedule of sexual reinforcement. Neuroscience 1989, 30, 63-75. [CrossRef]

109. Everitt, B.J.; Parkinson, J.A.; Olmstead, M.C.; Arroyo, M.; Robledo, P.; Robbins, T. Associative Processes in Addiction and Reward the Role of Amygdala-Ventral Striatal Subsystems. Ann. N. Y. Acad. Sci. 1999, 877, 412-438. [CrossRef]

110. Baxter, M.G.; Murray, E. The amygdala and reward. Nat. Rev. Neurosci. 2002, 3, 563-573. [CrossRef]

111. Murray, E.A. The amygdala, reward and emotion. Trends Cogn. Sci. 2007, 11, 489-497. [CrossRef]

112. Ramirez, D.R.; Savage, L.M. Differential involvement of the basolateral amygdala, orbitofrontal cortex, and nucleus accumbens core in the acquisition and use of reward expectancies. Behav. Neurosci. 2007, 121, 896-906. [CrossRef]

113. Harsay, H.A.; Spaan, M.; Wijnen, J.G.; Ridderinkhof, K.R. Error Awareness and Salience Processing in the Oddball Task: Shared Neural Mechanisms. Front. Hum. Neurosci. 2012, 6, 246. [CrossRef]

114. Liang, X.; He, Y.; Salmeron, B.J.; Gu, H.; Stein, E.A.; Yang, Y. Interactions between the Salience and Default-Mode Networks Are Disrupted in Cocaine Addiction. J. Neurosci. 2015, 35, 8081-8090. [CrossRef] [PubMed]

115. Rogers-Carter, M.; Christianson, J.P. An insular view of the social decision-making network. Neurosci. Biobehav. Rev. 2019, 103, 119-132. [CrossRef] [PubMed]

116. Rogers-Carter, M.M.; Djerdjaj, A.; Gribbons, K.B.; Varela, J.A.; Christianson, J.P. Insular Cortex Projections to Nucleus Accumbens Core Mediate Social Approach to Stressed Juvenile Rats. J. Neurosci. 2019, 39, 8717-8729. [CrossRef] [PubMed]

117. Barch, D.M. Nonsocial and social cognitive function in psychosis: Interrelationships, specificity and innovative approaches. World Psychiatry 2019, 18, 117-118. [CrossRef]

118. Kotov, R.; Jonas, K.G.; Carpenter, W.T.; Dretsch, M.N.; Eaton, N.R.; Forbes, M.K.; Forbush, K.T.; Hobbs, K.; Reininghaus, U.; Slade, T.; et al. Validity and utility of Hierarchical Taxonomy of Psychopathology (HiTOP): I. Psychosis superspectrum. World Psychiatry 2020, 19, 151-172. [CrossRef]

119. Rodgers, K.M.; Benison, A.M.; Klein, A.; Barth, D.S. Auditory, Somatosensory, and Multisensory Insular Cortex in the Rat. Cereb. Cortex 2008, 18, 2941-2951. [CrossRef]

120. Gogolla, N.; Takesian, A.E.; Feng, G.; Fagiolini, M.; Hensch, T.K. Sensory Integration in Mouse Insular Cortex Reflects GABA Circuit Maturation. Neuron 2014, 83, 894-905. [CrossRef]

121. Gogolla, N. The insular cortex. Curr. Biol. 2017, 27, R580-R586. [CrossRef]

122. Wright, C.; Groenewegen, H. Patterns of overlap and segregation between insular cortical, intermediodorsal thalamic and basal amygdaloid afferents in the nucleus accumbens of the rat. Neuroscience 1996, 73, 359-373. [CrossRef]

123. Wise, R.A. Brain Reward Circuitry: Insights from Unsensed Incentives. Neuron 2002, 36, 229-240. [CrossRef] 